\title{
Performance Analysis of Air Conditioner using R290 as Refrigerant with and Without Nanoparticles
}

\author{
M Manikanta \\ PG Scholar \\ Department of Mechanical Engineering, \\ JNTUA College of Engineering \\ Anantapuramu, India
}

\author{
M. L. S. Deva Kumar \\ Professor of Mechanical Engineering Department \\ \& \\ Director of JNTUA School of Management Studies \\ JNTUA College of Engineering \\ Anantapuramu, India
}

\begin{abstract}
R22 is commonly used refrigerant in air conditioning systems. These HCFC refrigerants have negative impact on the environment which causes ozone depletion. Hence the usage of these HCFC refrigerants needs to be avoided. An alternative refrigerant need to be evaluated as an alternative to these HCFC refrigerants and $\mathrm{R290}$ is suitable as alternative refrigerant due to its low ODP and low GWP.

In this, $\mathrm{Cu}$ doped $\mathrm{MgO}$ Nanoparticles are synthesized and the nanoparticles are used for the preparation of Nano-lubricant with different concentrations. An experimental investigation is performed on the air conditioner using $R 290$ as refrigerant with and without $\mathrm{Cu}$ doped $\mathrm{MgO}$ nanoparticles in compressor lubricant oil. The system performance is analyzed and compared with and without using nanoparticles based on the performance parameters such as refrigeration effect, compressor work input and COP.
\end{abstract}

Keywords- R22; R290; GWP; ODP; Nanoparticles; refrigeration effect;compressor work input; COP.

\section{INTRODUCTION}

To improve the coefficient of performance (COP) of the vapor compression refrigeration system (VCRS), different methods are adopted as reported in the literature. Bilir Nagihan and Kursad Ersoy (2009) have studied the role of a two-phase constant area of the ejector for improvement in the performance of a refrigeration system by recovering the kinetic energy at expansion process, and as a result reducing the compressor work. Sattar et al. (2007) has reported the performance improvement of a VCRS utilizing refrigerant R134a when various blends of hydrocarbons are used. With the advent of nanotechnology, in the literature survey, many have studied the effect of nanoparticles as additives, in refrigerant or in mineral oil used as the lubricant, on the COP of the VCRS. Park and Jung (2007) studied due to the addition of the carbon nanotubes the boiling heat transfer in refrigerants enhanced. Lee et al. (2009) has stated an improvement in the lubrication characteristics is found when the refrigeration mineral oil containing 0.1 vol. $\%$ of fullerene nanoparticles. Bi et al. (2008) studied that when $0.1 \%$ mass fraction of $\mathrm{TiO} 2$ nanoparticles in R134a and Polyolester (POE) oil system are used in the VCRS has reduced the power consumption about $26 \%$.

Stability of nanoparticles in suspension is one of the key issues which make the application of nanoparticles in refrigerants difficult, but it is also hard because the fluid undergoes a phase change in every cycle. Lubricants enhance the performance of a system in several ways when additives are added to it. When the nanoparticles are added to lubricants, the critical parameters improved are anti-friction, anti-wear, anti-corrosion, extreme pressure, detergent and anti-oxidant. With increasing complications in operating conditions and development in technology coupled with increasing lubrication requirements are the necessary factors for the exploration of the new kind of additives and optimum value of their concentrations. Nanoparticles are regarded as the most important prospect to meet these demands. The performance of composites, oils, fluids, etc. are enhanced due to the addition of nanoparticles, which is due to high surface area to volume ratio that is leading to the extensive interaction between tribo contact points and lubricants containing nanoparticles.

\section{PREPERATION OF NANO-LUBRICANT}

$\mathrm{MgO}$ is an important material that has wide range of applications in catalysis, toxic waste, remediation, paints, superconducting products and anti-bacterial activities. The $\mathrm{MgO}$ compound has boiling point about $3600^{\circ} \mathrm{C}$ and melting point as $2852^{\circ} \mathrm{C}$. These oxide materials can be synthesized by different methods like solution combustion, chemical precipitation, sol-gel, hydrothermal, solyothermal, microwave assisted sol-gel, and green synthesis etc. Among these methods, co-precipitation method is one of the best methods to synthesis nanoparticles without agglomeration in the production.

$\mathrm{Cu}$ doped $\mathrm{MgO}$ nanoparticles will be prepared by Coprecipitation method. The samples were synthesized under laboratory conditions in clean room and analyzed using such as X-ray Diffraction (XRD) and Scanning Electron Microscopy (SEM).

\section{A. Synthesis and Analysis of $\mathrm{Cu}$ doped $\mathrm{MgO}$ Nanoparticles}

- Prepare a solution mixture of 0.6M Magnesium Chloride and 0.01M Copper Chloride. Also prepare $0.1 \mathrm{M} \mathrm{KOH}$ solution.

- Mix KOH solution drop wise to the mixture solution of Magnesium Chloride and Copper Chloride and kept under constant stirring for three hours then we obtain a green bluish thick solution. 
- Then the solution is filtered and we obtain green bluish precipitate.

- The precipitate is dried in oven at $100^{\circ} \mathrm{C}$ for three hours and then calcinated at $200^{\circ} \mathrm{C}$ for 2 hours. Thus $\mathrm{Cu}$ doped $\mathrm{MgO}$ Nanoparticles are obtained.

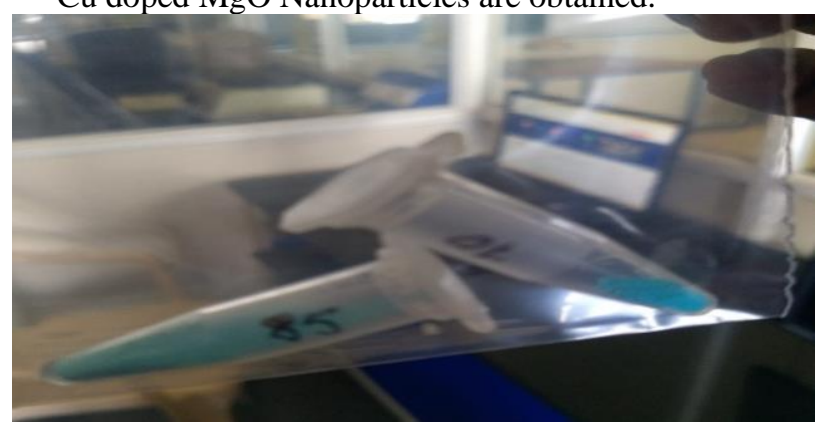

Fig. 1. $\mathrm{Cu}$ doped $\mathrm{MgO}$ Nanoparticles

- The prepared sample particles were in the range between $20.27 \mathrm{~nm}$ to $30.67 \mathrm{~nm}$ which is below $100 \mathrm{~nm}$ and it was established from X-diffraction.

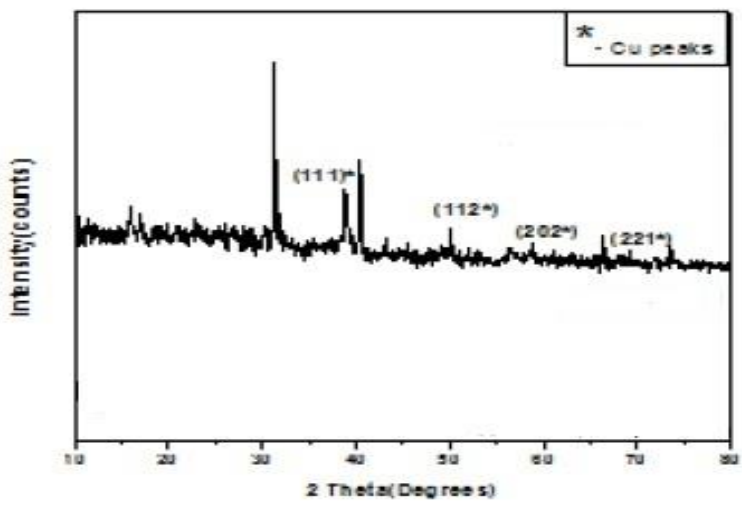

Fig. 2. XRD result of $\mathrm{Cu}$ doped $\mathrm{MgO}$ Nanoparticles

- SEM analysis of the $\mathrm{Cu}$ doped $\mathrm{MgO}$ shows that the nanoparticles are agglomerated due to the defects created by $\mathrm{Cu}$ doping. With the increase in the dopant concentration, the agglomeration of particles takes place. Thereby the size of the nanoparticles will be increased when compared with pure $\mathrm{MgO}$ nanoparticles.

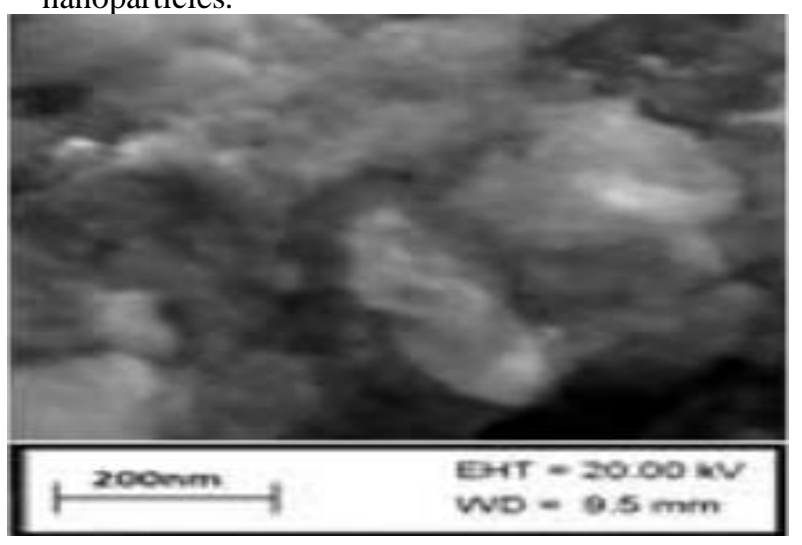

Fig. 3. SEM Image of $\mathrm{Cu}$ doped $\mathrm{MgO}$ Nanoparticles

\section{B. Preparation of $\mathrm{Cu}$ doped $\mathrm{MgO}$ Nanolubricant}

$\mathrm{Cu}$ doped $\mathrm{MgO}$ nanoparticles are added to the compressor lubricant oil in the refrigeration system. The preparation and stability of this lubricant and nanoparticle mixture is more important to the given study. The lubricant oil, commonly used in the refrigeration systems was POE oil. This oil is selected owing to its common usage and superior quality.

Ultrasonic vibration method is used to stabilize the dispersion of the nanoparticles in the lubricant. The steps are involved in the preparation of nano-lubricant is as follows:

- $\mathrm{Cu}$ doped $\mathrm{MgO}$ nanoparticles are weighed using digital electronic balance with the measurement ranging from $12 \mathrm{mg}$ to $200 \mathrm{mg}$.

- Add $\mathrm{Cu}$ doped $\mathrm{MgO}$ nanoparticles into the POE oil and get the $\mathrm{Cu}$ doped $\mathrm{MgO} / \mathrm{POE}$ oil.

- By using an ultrasonic vibrating system, the mixture is vibrated for few hours and as a result $\mathrm{Cu}$ doped $\mathrm{MgO}$ nanoparticles will get dispersed well into the lubricant oil. The surfactant is not added to this mixture because it may decrease the thermal conductivity and the performance of the system.

- The oil container is kept in the magnetic stirrer to get the homogenization of nano-lubricant. Nano-particles $(\mathrm{Cu}$ doped $\mathrm{MgO})$ with $0.2,0.3$ and $0.4 \mathrm{vol} . \%$ is added to the POE oil and tested in the setup are prescribed.

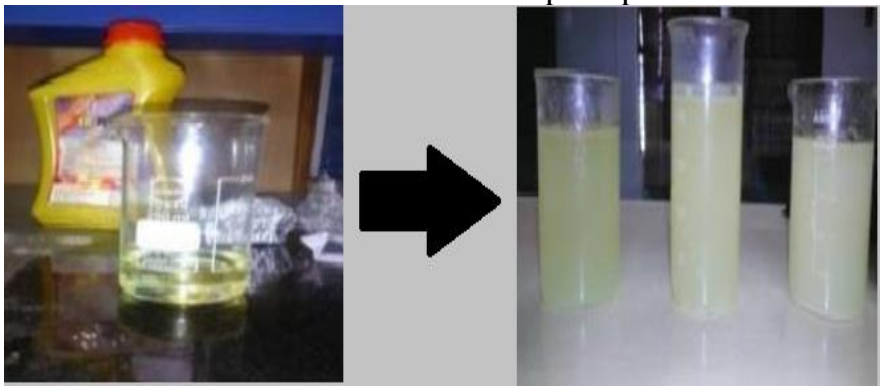

Fig. 4. Pure POE oil with $\mathrm{Cu}$ doped $\mathrm{MgO}$ Nanoparticles $[0.2 \%, 0.4 \%, 0.6 \%$ vol.]

\section{EXPERIMENTAL WORK}

The study was conducted on air conditioning test rig. The test rig consists of a compressor, air-cooled condenser, capillary tube and an evaporator.

The compressor was hermetically sealed reciprocating compressor and the evaporator made of copper. The heat flux was supplied to evaporator by means of heater $(230 \mathrm{~W})$ and automatic stirrer to continuously stir the water. The condenser was cooled using fan.

The pressure gauges were installed at the salient point of the refrigeration system. Thermocouples were used to measure temperature at various location of the flow of refrigerant. The power consumption by the compressor was measured using energy meter. The heater power regulator is provided to adjust constant heat flux and maintained steady state condition.

The test rig was filled with $\mathrm{N}_{2}$ gas at a pressure of $200 \mathrm{psi}$ and this pressure was maintained for $5 \mathrm{hrs}$. The system was checked for the leakages thoroughly using traditional soap bubble method and ensured for no leakages. The system was evacuated by removing $\mathrm{N}_{2}$ gas. A vacuum pump was connected to the port provided in the compressor and the 
system was completely evacuated for the removal of any impurities. This process was carried out for all the trials. The compressor was filled with the POE oil and the refrigerant R290 was charged through the charging line to the compressor. Every time the system was allowed to stabilize for 15 minutes.

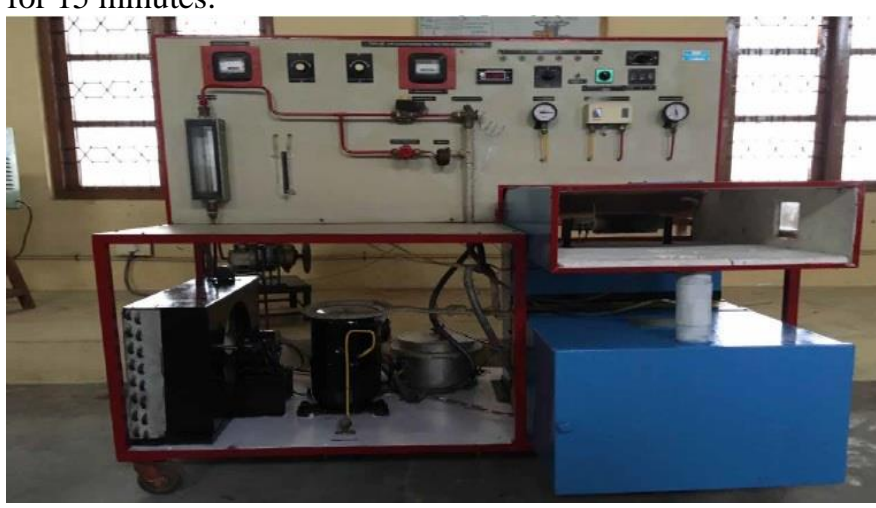

Fig. 5. Air Conditioner Test Rig

The tests are conducted on the air conditioner test rig in the following cases by maintained the evaporator exit temperature $\mathrm{T}_{1}$ constant at $20^{\circ} \mathrm{C}, 25^{\circ} \mathrm{C}$, and $30^{\circ} \mathrm{C}$ :

Case I: Air conditioning system using R290 as refrigerant and POE oil as compressor lubricant.

Case II: Air conditioning system using R290 as refrigerant and POE oil with $\mathrm{Cu}$ doped $\mathrm{MgO}$ nanoparticle $(0.2 \%$ Vol.) as lubricant.

Case III: Air conditioning system using R290 as refrigerant and $\mathrm{POE}$ oil with $\mathrm{Cu}$ doped $\mathrm{MgO}$ nanoparticle (0.4\% Vol.) as lubricant.

Case IV: Air conditioning system using R290 as refrigerant and POE oil with $\mathrm{Cu}$ doped $\mathrm{MgO}$ nanoparticle (0.6\% Vol.) as lubricant.

\section{RESULTS AND DISCUSSION}

\section{A. Comparision of Net Refrigeration Effect}

When the air conditioning system is operated at constant evaporator exit temperature $\left(\mathrm{T}_{1}\right)$ of about $20^{\circ} \mathrm{C}$, with the increase in concentration of the nanoparticles in the lubricant oil, the Net Refrigeration Effect of the system increased from $345.154 \mathrm{~kJ} / \mathrm{kg}$ to $350.3 \mathrm{~kJ} / \mathrm{kg}$. Similarly when the $\mathrm{T}_{1}$ is maintained at $25^{\circ} \mathrm{C}$ and $30^{\circ} \mathrm{C}$, the Net Refrigeration Effect of the system increased from $349.532 \mathrm{~kJ} / \mathrm{kg}$ to $361.999 \mathrm{~kJ} / \mathrm{kg}$ and from $352.437 \mathrm{~kJ} / \mathrm{kg}$ to $371.05 \mathrm{~kJ} / \mathrm{kg}$ respectively. Hence the percentage increase in the Net Refrigeration Effect of the system when $\mathrm{T}_{1}$ is maintained at $20^{\circ} \mathrm{C}, 25^{\circ} \mathrm{C}$, and $30^{\circ} \mathrm{C}$ is $1.49 \%, 3.57 \%$ and $5.28 \%$ respectively.

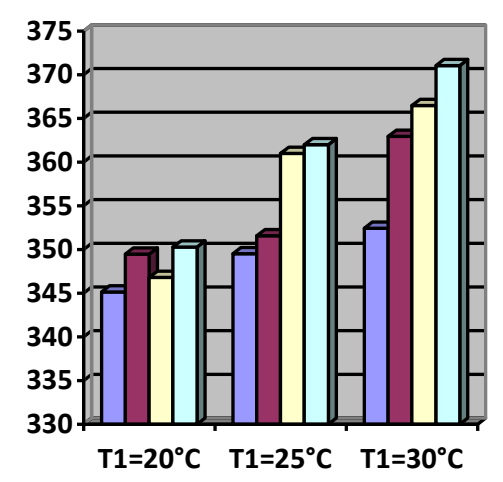

\begin{tabular}{|l|}
\hline$\square$ R290 + POE oil \\
$\square$ R290 + POE + \\
$0.2 \%$ vol. of \\
nanoparticles \\
$\square$ R290 + POE + \\
$0.4 \%$ vol. of \\
nanoparticles \\
$\square$ R290 + POE + \\
$0.6 \%$ vol. of \\
nanoparticles \\
\hline
\end{tabular}

Fig. 6. Comparison of Net Refrigeration Effect

\section{B. Comparision of Compressor Work Input}

When the air conditioning system is operated at constant evaporator exit temperature $\left(\mathrm{T}_{1}\right)$ of about $20^{\circ} \mathrm{C}$, with the increase in concentration of the nanoparticles in the lubricant oil, the power input to the system decreased from 81.711 $\mathrm{kJ} / \mathrm{kg}$ to $77.956 \mathrm{~kJ} / \mathrm{kg}$.

Similarly when the $\mathrm{T}_{1}$ is maintained at $25^{\circ} \mathrm{C}$ and $30^{\circ} \mathrm{C}$, the power input to the system decreased from $80.452 \mathrm{~kJ} / \mathrm{kg}$ to $79.057 \mathrm{~kJ} / \mathrm{kg}$ and from $80.374 \mathrm{~kJ} / \mathrm{kg}$ to $78.591 \mathrm{~kJ} / \mathrm{kg}$ respectively. Hence the percentage decrease in the power input to the system when $\mathrm{T}_{1}$ is maintained at $20^{\circ} \mathrm{C}, 25^{\circ} \mathrm{C}$, and $30^{\circ} \mathrm{C}$ is $4.6 \%, 1.73 \%$ and $2.22 \%$ respectively.
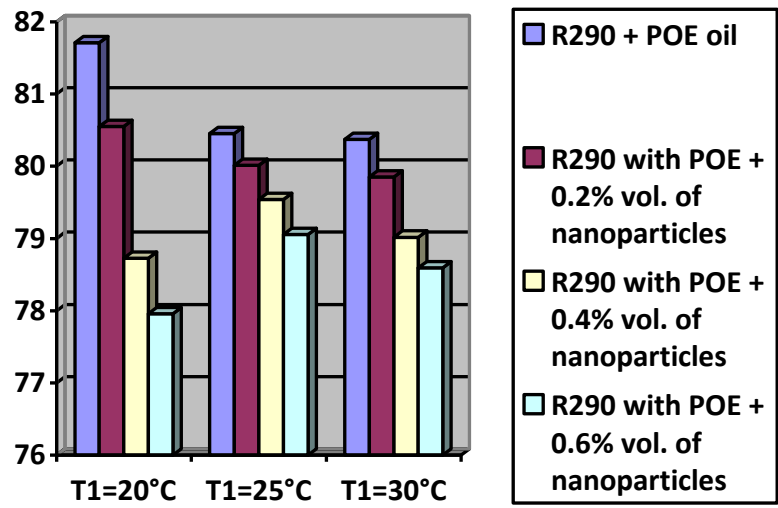

Fig. 7. Comparison of Compressor Work Input

\section{Comparision of Compression Pressure Ratio}

The compression ratio of the system increases with the increase in the volume concentration of the $\mathrm{Cu}$ doped $\mathrm{MgO}$ nanoparticles in the POE lubricant oil. As the evaporator temperature increases from $20^{\circ} \mathrm{C}$ to $30^{\circ} \mathrm{C}$ and the nanoparticles concentration increases from $0 \%$ to $0.6 \%$ in lubricant oil, the compression ratio increased from 3.671 to 5.417 . 


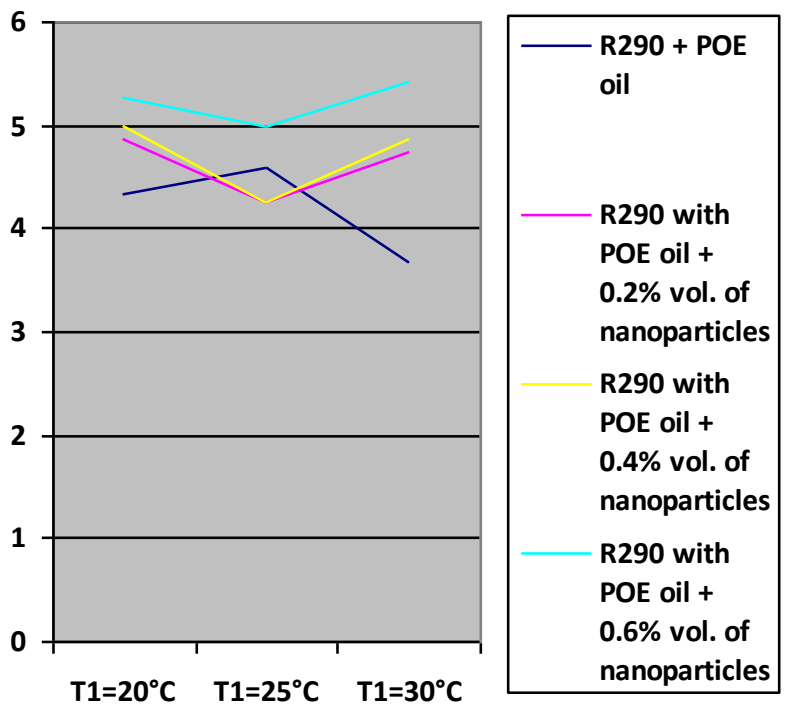

Fig. 8. Comparison of Compressor Pressure Ratio

\section{Comparision of Coefficient of Performance (COP}

When the air conditioning system is operated at constant evaporator exit temperature $\left(\mathrm{T}_{1}\right)$ of about $20^{\circ} \mathrm{C}$, with the increase in concentration of the nanoparticles in the lubricant oil, the COP of the system increased from 4.22 to 4.499 .

Similarly when the $\mathrm{T}_{1}$ is maintained at $25^{\circ} \mathrm{C}$ and $30^{\circ} \mathrm{C}$, the COP of the system increased from 4.345 to 4.759 and from 4.545 to 4.721 respectively. Hence the percentage increase in the power input to the system when $\mathrm{T}_{1}$ is maintained at $20^{\circ} \mathrm{C}$, $25^{\circ} \mathrm{C}$, and $30^{\circ} \mathrm{C}$ is $6.611 \%, 5.385 \%$ and $7.669 \%$ respectively.

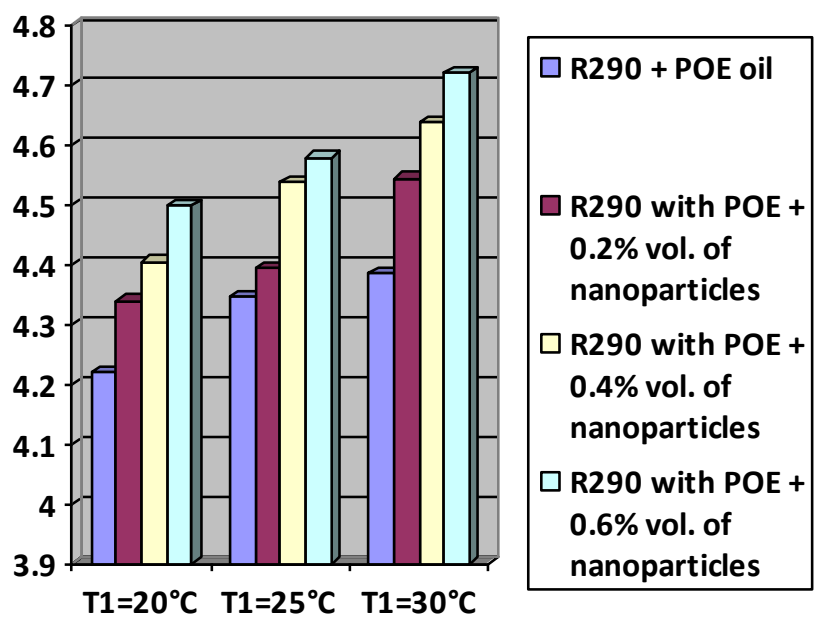

Fig. 9. Comparison of COP

\section{CONCLUSION}

The study results statement and its contributions are concluded in following points:

- A hybrid nanoparticle $\mathrm{Cu}$ doped $\mathrm{MgO}$ is synthesized and it is used to prepare the nano-lubricant that reduces the compressor work.

- Nanolubricant is prepared by mixing the $\mathrm{Cu}$ doped $\mathrm{MgO}$ nanoparticles at $0.2 \%$ vol., $0.4 \%$ vol., and $0.6 \%$ vol. concentrations with the polyester oil.

- The performance of the refrigeration system is evaluated by maintaining the evaporator temperature at $20^{\circ} \mathrm{C}, 25^{\circ} \mathrm{C}$ and $30^{\circ} \mathrm{C}$.

- COP is increased when R290 along with nanolubricant is used in the VCRS as compared to that of only R290 refrigerant.

- It is observed that the compressor work input decreased from $81.711 \mathrm{~kJ} / \mathrm{kg}$ to $78.591 \mathrm{~kJ} / \mathrm{kg}$ as the concentration of the lubricant oil increased from $0 \%$ vol. to $0.6 \%$ vol.

- The increase in COP of system when $0.2 \%$ vol. and $0.6 \%$ vol. of nanoparticles is used more when compared to the increase in COP of system when $0.4 \%$ vol. of nanoparticles.

- The maximum increase in the COP of the system is $7.669 \%$ and it is observed when $0.6 \%$ vol. of the $\mathrm{Cu}$ doped $\mathrm{MgO}$ nanoparticles with $\mathrm{POE}$ oil at $30^{\circ} \mathrm{C}$ of evaporator temperature. The least increase in COP of system is 1.128 and it is observed when $0.4 \%$ vol. of the $\mathrm{Cu}$ doped $\mathrm{MgO}$ nanoparticles at $25^{\circ} \mathrm{C}$ of evaporator temperature.

\section{REFERENCES}

[1] Sattar MA, Saidur R, Masjuki HH, "Performance investigation of domestic Refrigerator using pure hydrocarbons and blends of hydrocarbons as refrigerants," World Acad. Sci., Eng. Technol, 29, 2007, 223-228.

[2] Park, Ki Jung, Jung, Dongsoo, "Boiling heat transfer enhancement with carbon nanotubes for refrigerants used in building air-conditioning," Energy and Buildings, 39, 2007, 1061-1064.

[3] Lee, Kwangho, Hwang, Yujin, Cheong, Seongir, Kwon, Laeun, Kim, Sungchoon, Lee, Jaekeun, "Performance evaluation of nano-lubricants of fullerene nanoparticles in refrigeration mineral oil," Current Applied Physics, vol. 9, 2009, 128-131.

[4] Bi, Sheng shan, Shi, Lin, Zhang, Li, "Application of nanoparticles in domestic refrigerators," Appl. Thermal Eng., 28, 2008, 1834-1843.

[5] D. Senthilkumar, "Influence of Silicon Carbide Nanopowder in R134a Refrigerant Used in Vapor Compression Refrigeration System," vol. 25, no. 1, pp. 1-10, 2017.

[6] R. Kumar and J. Singh, "Effect of ZnO nanoparticles in R290 / R600a ( 50 / 50 ) based vapour compression refrigeration system added via lubricant oil on compressor suction and discharge characteristics," Heat Mass Transf., vol. 53, no. 5, pp. 1579-1587, 2017.

[7] K. Mani and V. Selladurai, "Experimental analysis of a new refrigerant mixture as dropin replacement for CFC12 and HFC134a," Int. J. Therm. Sci., vol. 47, no. 11, pp. 1490-1495, 2008.

[8] M. E. Haque, R. A. Bakar, K. Kadirgama, M. M. Noor, and M. Shakaib, "Performance of a domestic refrigerator using nanoparticlesbased polyolester oil lubricant,” J. Mech. Eng. Sci., vol. 10, no. 1, pp. 1778-1791, 2016 